\title{
A Choice Experiment Study on Fuel Preference of Kibera Slum Households in Kenya
}

\author{
Aya Yonemitsu, Mary Njenga, Miyuki Iiyama, and Shusuke Matsushita
}

\begin{abstract}
In Kenya, charcoalis an important energy resource for cooking. As better energy alternatives become available and affordable in developing countries, households tend to switch from traditional biomass to modern fuels such as liquid petroleum gas, kerosene, and electricity.Meanwhile, fuel briquettes recycled from charcoal dust are gaining popularity as alternate fuel in urban poor households. The valuing of energy services is important for policy planning and for improving the socioeconomic conditions and environments of households. The objective of this study is to better understand the relative importance of fuel substitution, especially with regard to charcoal, fuel briquettes, and kerosene, and the factors associated with their choice. To estimate the product-specific factors, we conduct a choice experiment study in Kibera slums of Nairobi, Kenya, by applying a conditional logit model and random parameter logit model. The study revealed household preferences for modern energy sources and several characteristics affecting consumer choice.
\end{abstract}

Index Terms-Charcoal, charcoal briquettes, Kenya, fuel consumption, biomass energy, urban poor.

\section{INTRODUCTION}

Woody biomass, especially charcoal, is an important energy source in Kenya. Urban households in informal settlements rely almost entirely on charcoal for their basic cooking energy needs [1]-[4]. Charcoal is preferred because it produces less smoke, its calorific value is twice that of wood, and it lasts longer, especially when used with improved cooking stoves. Moreover, charcoal is considered affordable, economical, and convenient and has an extensive distribution network that ensures its availability in informal settlements. Thus, charcoal is one of the options of cooking fuels for many poor residents. A previous study showed that the world production of charcoal in 2004 was 1.6 million tons [4]. Population increases and urbanization have led to the increased demand for charcoal in sub-Saharan Africa (SSA). This trend, coupled with the inefficient charcoal production and consumption technologies and households' inaccessibility to other modern energy sources, is not likely to change in the near future [5].

Charcoal production is considered the major cause of deforestation, mostly on account of unsustainable harvesting and inefficient production techniques [6], [7]. For instance,

Manuscript received May 25 2014; revised July 17, 2014.

Aya Yonemitsu is with Graduate School of Life and Environmental Sciences, University of Tsukuba, Tsukuba, Japan (e-mail: aya.yonemitsu@gmail.com).

Mary Njenga and Miyuki Iiyama are with World Agroforestry Centre (ICRAF), P.O. Box 30677-00100, Nairobi, Kenya.

Shusuke Matsushita is with the Faculty of Life and Environmental Sciences, University of Tsukuba, Tsukuba, Japan. only $10-20 \%$ of the raw wood is converted to charcoal during the production process because of the use of inefficient kilns. Further, about $10-15 \%$ of charcoal is wasted along the supply chain to form dust or fines from breakages during handling; this dust can be mainly found at the retail and wholesale stalls [8]. Faced with the disposal challenges of charcoal dust, slum communities turn to making charcoal briquettes with the dust recovered from among the other organic by-products. The dust has considerable energy value and can be recycled into fuel briquettes. In Kenya, the use of fuel briquettes is spreading among the urban and rural households and there is a huge potential for briquettes to become an affordable and good cooking fuel. Charcoal briquettes have been found to be environmentally beneficial since they produce less smoke, increase the total cooking energy by more than $15 \%$, and thereby save an equivalent volume of trees that would otherwise be cut down for charcoal [9].

Substituting charcoal with electricity and/or liquid petroleum gas (LPG) should be one of the remedies to reduce the pressures of deforestation and health risks from indoor pollution [1]. With regard to the relationship between household economic growth and energy consumption, some empirical and micro-level studies have presented the "energy ladder' hypothesis, which states that an increase in income helps households shift their energy sources from traditional biomass to modern fuels [10]-[12]. However, differing with the energy ladder hypothesis, there is an argument that households in developing countries do not switch to modern energy sources but rather tend to consume a combination of fuels [13], [14]. A study on Ethiopia has shown that households do not switch completely from biomass to modern fuels, but rather increase the number of fuels used as their total expenditure rises [15], [16]. We consider it crucial to understand the factors that affect the consumption patterns of cooking energy, that is, the substitution and diversification of energy sources, of the lower-income urban households in SSA, rather than simply assuming the energy ladder hypothesis. We need a more policy-relevant and realistic theory of household energy demand, because the benefit of policies that ignore fuel stacking may be less than hypothesized. In fact, only a few studies have seriously examined the multiple fuel use in SSA. The causes of fuel stacking in Kenya are also not well understood, although we know that increases in population, economic growth, and urbanization have led to an increasing energy demand in Kenya. Therefore, we need to analyse the transition from charcoal to kerosene, which is the most important modern energy option for the poor in Nairobi, and the adoption of charcoal briquette as a substitute/complement to charcoal.

The primary aim of this study is to better understand the relative importance of fuel substitution and fuel complementation, especially with regard to charcoal, fuel 
briquettes, and kerosene. More specifically, we analyse the determinants of the fuel preferences of urban poor households. For this, we use a choice experiment based on a stated preference survey of slum dwellers of Nairobi and a conditional logit (CL) model and a random parameter logit (RPL) model.

\section{Methodology AND ApPROACH}

\section{A. Study Sites and Approach}

We conduct our study in Nairobi, Kenya, located $1^{\circ} 00^{\prime} \mathrm{N}$ and $30^{\circ} 00^{\prime \prime} \mathrm{E}$ in southern Kenya at an elevation of $1670 \mathrm{~m}$ above sea level and covering an area of 700 square kilometres. We estimate the city's population at three million, with an annual growth rate of $2.8 \%$ between 2000 and 2015, constituting $7.5 \%$ of the country's population [8]. Sixty per cent of the city's population live in low-income informal settlements, and the urban poor is projected to increase to $65 \%$ by 2015 [17]. These settlements comprise one of the most densely populated informal settlements in the world and Africa's largest slum. The exact number of people living in this slum area is not clear, as the 1999 census showed the figure close to one million whereas the 2009 census figure stood at 0.4 million within an area of 2.5 square kilometres. Owing to the high density of the settlements, unplanned residential areas, and crowded houses, as well as the lack of infrastructure, the settlements' acute problems of drainage, sanitation, and solid waste management have been worsening continuously. The fuel use and demand patterns of Kibera's households largely depend on their end uses such as cooking and lighting, as well as the energy uses of home-based commercial and productive activities in small micro-enterprises (SMEs) [18].

We conducted a household survey in the Gatwekera and Kisumu villages in the Kibera slums during December 2011. The households in the villages are able to choose briquettes as an energy option because of the presence of briquette production sites or retail shops in the region. We selected 25 households randomly along four footpaths in each village and interviewed a total of 200 villagers. The households were selected by picking every fifth one on each footpath located within a radius of $250 \mathrm{~m}$ from the market street.

\section{B. Choice Experiment Design}

We employed the orthogonal main-effects design in this study; this design is effective in terms of isolating the effects of individual attributes on a choice. The ability to incorporate orthogonality into the $\mathrm{CE}$ design is an important advantage over revealed preference random utility models.

Table I shows the attributes, namely, the price and distance to buy, expressed quantitatively for varying levels. As the table shows, the choices offered to respondents include three labelled ones and the 'neither' option. If neither of the fuel profiles was found satisfactory, the respondent could identify neither as the 'do not buy option'. We assigned four levels to the price attributes in each choice: the ranges of levels were estimated based on market information gathered from our pilot survey conducted in August 2011.

Using the orthogonal main-effects design with R statistics software, our final design consisted of 24 choice sets. However, since the 24 sets were too large for each respondent to answer, we randomly divided the sets into four subsets of six choice sets each. We then randomly allotted the respondents interviewed to subsets $\mathrm{A}, \mathrm{B}, \mathrm{C}$, or $\mathrm{D}$, and by completing a subset, each respondent had to select a preferred option from the four possible choices in the six choice sets. Table II shows an example of a choice set actually used in the questionnaire.

TABLE I: ALLOCATION OF LEVELS AND LABELS FOR THE TWO ATTRIBUTES

\begin{tabular}{llll}
\hline & Briquettes & Charcoal & Kerosene \\
\hline Price (Ksh) & $\{1,2,3,4\}$ per 1 block & $\{15,25,35,45\}$ per 2 kg & $\{80,90,100,110\}$ per litre \\
Distance (minute) & $\{15,30\}$ minutes walk & $\{15,30\}$ minutes walk & $\{15,30\}$ minutes walk \\
\hline
\end{tabular}

TABLE II: EXAMPLE OF CHOICE SET FROM THE HOUSEHOLD SURVEY IN

\begin{tabular}{lllll}
\multicolumn{4}{c}{ KIBERA } \\
\hline Price & Ksh.1 /block & Ksh.25/2kg tin & Ksh.110/liter \\
Distance & 15 minutes & 30 minutes & 30 minutes & \\
\hline
\end{tabular}

\section{Model Specification}

We used the random utility model in this study to explain individual choices by specifying the functions of the utility derived from the available alternatives. A conditional logit model (CL), developed by McFadden [19], is recommended as the first step in determining the right attributes and their functional forms. The indirect utility function of individual $n$ who chooses alternative $i$ in the choice set can be expressed as

$$
U_{\text {in }}=V_{\text {in }}+\varepsilon_{\text {in }} .
$$

This utility function, $U_{i n}$, can be decomposed into a deterministic part, $V_{i n}$, and a stochastic part, $e_{i n}$.Furthermore, if $U_{i n}>U_{j n}$ for all $i \neq j$ in the choice set $\mathrm{C}$, the probability that individual $n$ will choose alternative $i$ can be given by

$$
P_{i n}=P\left\{V_{i n}+\varepsilon_{i n}>V_{j n}+\varepsilon_{j n} ; \text { for all } j \epsilon C(i \neq j)\right\} .
$$

The probability of individual $\mathrm{n}$ selecting alternative $i$ from choice set $C_{n}$ in the CL model can be shown as follows:

$$
P(i)=\exp \left(V_{i n}\right) / \sum_{j \epsilon C_{n}} \exp \left(V_{j n}\right) .
$$

$V_{\text {in }}$ is a systematic component of utility usually assumed to be a linear additive function of the independent variables $X_{i k}$ with coefficients $\beta_{i k}$ :

$$
V_{\text {in }}=\sum_{k=1}^{K} \beta_{i k} X_{i k} .
$$

In order to test the effect of the relevant individual characteristics on choice, we introduce socioeconomic variables into $\mathrm{Eq}$ (4). This model can be expressed as

$$
V_{\text {in }}=\sum_{k=1}^{K} \beta_{i k} X_{i k}+\sum_{k=1}^{K} \sum_{h=1}^{H} \gamma_{k h} X_{i k} S_{h n}
$$

The classical economic specification for estimating CE, the conditional logit model, is generally overcome by the random parameter logit (RPL) model (Train, 2003). In the RPL model a random term whose distribution over 
individuals depends on under lying parameters is added to a classical utility function associated with alternative. Unlike
CL model, RPL model allows for the specification of unobserved heterogeneity among individuals.

TABLE III: SOCIOECONOMIC CONDITONS OF SURVEYED HOUSEHOLDS

\begin{tabular}{|c|c|c|c|c|}
\hline & Mean & Std. dev. & Min. & Max. \\
\hline Sample size & 187 & & & \\
\hline \multicolumn{5}{|l|}{ Household size and composition } \\
\hline Household size (persons) & 4.67 & 1.76 & 2 & 10 \\
\hline Female-headed households (\%) & 15.51 & & & \\
\hline Household head age (years) & 34.65 & 9.52 & 20 & 69 \\
\hline Education level of household head (years) & 9.82 & 2.62 & 2 & 19 \\
\hline Children below 5 years of age (person) & 0.96 & 0.86 & 0 & 5 \\
\hline Children aged between 5-14 years (person) & 1.19 & 1.24 & 0 & 6 \\
\hline \multicolumn{5}{|l|}{ Income source (\%) } \\
\hline Regular salaried & 28.90 & & & \\
\hline Casual labouring & 54.00 & & & \\
\hline SME & 50.80 & & & \\
\hline Annual Income (Ksh) & 151,288 & 155,660 & 6,000 & $1,056,000$ \\
\hline
\end{tabular}

Source: Household survey conducted by the authors in 2010.

The marginal willingness to pay (MWTP) for a non-monetary variable is calculated as bnm/bm, where, bnm is the estimated coefficient of the non-monetary variable and bm the estimated coefficient of a monetary variable. Further, the confidence intervals for the MWTP are frequently calculated by using a simulation method based on a vector of means and the variance-covariance matrix of estimates developed by Krinsky and Robb [20].

\section{Methodology AND APPROACH}

\section{A. Descriptive Analysis}

We conducted a total of 200 person-to-person interviews, from which 187 were valid for further examination. The socioeconomic conditions of these 187 surveyed households (13 responses were invalid) are presented in Table III. The average size of a slum household was 4.67 persons and average age of the household head 34 years. Most of the household heads were male; female-headed households accounted for only $15.5 \%$ of all households. The average number of children below the age of 14 was 1.2 . The average household income was $151,288 \mathrm{Ksh} /$ year, which is far below the poverty line of 1.25 USD a day.

\section{B. Estimation Results}

The estimation results of CL and RPL models are presented in Table IV. An important increase of log-likelihood implies an improved overall fit of RPL model, compared to CL model. Additionally, what distinguishes RPL model as an advanced model from CL model is the highly significant standard deviation of the random parameters at $1 \%$ level, indicating that there is a structural advantage in RPL model.

In RPL model, we supposed alternative-specific constants for briquettes, charcoal and kerosene have independent normal distributions. All four entering the estimation proved to be significant. As expected, the coefficient for the PRICE attribute is negative and statistically significant. The higher the price, the lower is the probability that a respondent will select the alternative. The variable BRI and CHAR have significantly negative coefficients, indicating that the respondents evaluated them lower than kerosene. Next, the coefficient estimates for all cross effects except for the interaction between DIST and socioeconomic demographic variables in the cross effect model are also statistically significant at least at the 5\% level. Moreover, their signs of annual income are consistent with our expectation. The effects of BRI: INCOME and CHAR: INCOME are negative. This means that as the level of household income increases, the probability of households choosing kerosene over woody biomass also increases. This result also shows the effect of household heads' gender on the choice of briquettes and charcoal. From the signs of the coefficients, we find that female-headed households prefer briquettes and charcoal to kerosene. The DIST: FEMALE term is not significant, suggesting that a preference for distance to retail shop is not associated. The effect of DIST: INCOME is low in magnitude and not significant with a negative sign. The estimation results of the MWTP are contained in Table V. In the model, compare to kerosene, the MWTPs for briquettes and charcoal are negative values. However, the MWTPs for briquettes and charcoal valued by female headed households are calculated to be Ksh. 0.937 and Ksh. 0.367 per household. The results also shows that the effect of the households' income level on their valuation of the fuels. The coefficients of the interaction terms of between annual income and briquettes/charcoal are significantly different from zero.

\section{CONCLUSION}

In this study, we combined a choice experiment using a stated preference survey on the Kibera slums and RPL model to estimate the product-specific and socioeconomic factors influencing fuel choice. 
TABLE IV: EsTIMATION Results OF THE CONDITIONAL Logit (CL) MOdel AND tHE RANDOM PARAMETER (RPL) MODEL

\begin{tabular}{|c|c|c|c|c|c|}
\hline \multirow{2}{*}{ Attributes } & & \multicolumn{2}{|l|}{$\mathrm{CL}$} & \multicolumn{2}{|l|}{ RPL } \\
\hline & & Coefficient & Std. error & Mean coefficient & Std. error \\
\hline \multicolumn{6}{|l|}{ Main effects } \\
\hline BRI & dummy variable (Briquettes=1) & $-3.01 \mathrm{E}+00 * * *$ & $4.51 \mathrm{E}-01$ & $-5.69 \mathrm{E}+00 * * *$ & $6.97 \mathrm{E}-01$ \\
\hline CHAR & dummy variable $($ Charcoal $=1)$ & $-1.95 \mathrm{E}+00 * * *$ & 4.02E-01 & $-3.52 \mathrm{E}+00 * * *$ & $6.06 \mathrm{E}-01$ \\
\hline DIST & walking time to retail shop & $-3.96 \mathrm{E}-02 * * *$ & $6.46 \mathrm{E}-03$ & $-6.07 \mathrm{E}-02 * * *$ & $1.05 \mathrm{E}-02$ \\
\hline PRICE & price per MJ & $-1.45 \mathrm{E}+00 * * *$ & $1.82 \mathrm{E}-01$ & $-2.32 \mathrm{E}+00 * * *$ & $2.80 \mathrm{E}-01$ \\
\hline \multicolumn{6}{|l|}{ Cross effects } \\
\hline \multicolumn{6}{|c|}{ Female headed households (yes=1) } \\
\hline BRI: FEMALE & & $1.20 \mathrm{E}+00 * * *$ & $2.94 \mathrm{E}-01$ & $2.14 \mathrm{E}+00 * * *$ & 4.04E-01 \\
\hline CHAR: FEMALE & & $6.45 \mathrm{E}-01 * *$ & $2.90 \mathrm{E}-01$ & $8.59 \mathrm{E}-01 * *$ & $3.84 \mathrm{E}-01$ \\
\hline DIST: FEMALE & & $-1.17 \mathrm{E}-02$ & $1.39 \mathrm{E}-02$ & $-1.40 \mathrm{E}-02$ & 2.04E-02 \\
\hline \multicolumn{6}{|l|}{ Annual income } \\
\hline BRI: INCOME & & $-1.82 \mathrm{E}-06 * * *$ & $5.53 \mathrm{E}-07$ & $-2.50 \mathrm{E}-06 * * *$ & 8.09E-07 \\
\hline CHAR: INCOME & & $-7.27 \mathrm{E}-07 * *$ & $2.96 \mathrm{E}-07$ & $-9.32 \mathrm{E}-07 * *$ & 4.02E-07 \\
\hline DIST: INCOME & & 7.72E-09 & $2.50 \mathrm{E}-08$ & $4.21 \mathrm{E}-09$ & $3.74 \mathrm{E}-08$ \\
\hline \multicolumn{6}{|c|}{ Standard deviation of random parameters } \\
\hline BRI & & & & $2.92 \mathrm{E}+00 * * *$ & $2.70 \mathrm{E}-01$ \\
\hline CHAR & & & & $1.58 \mathrm{E}+00 * * *$ & $1.90 \mathrm{E}-01$ \\
\hline DIST & & & & $6.31 \mathrm{E}-02 * * *$ & $1.43 \mathrm{E}-02$ \\
\hline Log-Likelihood & & -1029.2 & & -864.41 & \\
\hline$\rho^{2}$ & & 0.0769 & & 0.22473 & \\
\hline
\end{tabular}

TABLE V: MARginAL WILLINGNESS TO PAY (MWTP) EstimATES AND CONFIDENCE INTERVALS

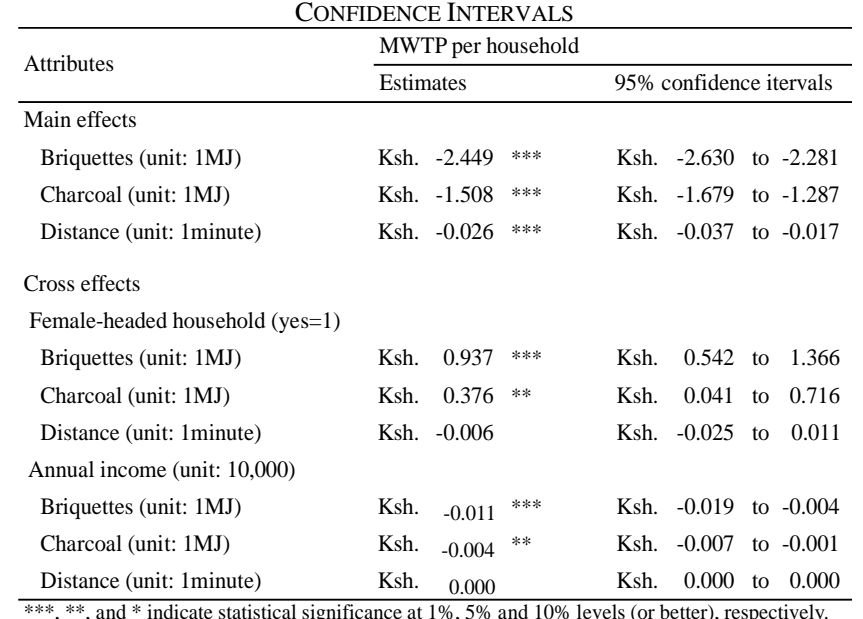

The model results showed that households evaluate briquettes and charcoal lower than kerosene. In the cross effect model, the household heads' gender and household income affect the choice of fuels and their MWTP. The results were broadly consistent with the energy ladder theory, by which consumers or households tend to choose a modern energy source as their wealth increases.

From this survey, the mean MWTP estimations for the RPL model with socioeconomic variable influences suggest that female-headed households as well as lower-income households prefer charcoal briquettes. In contrast, the households with higher income would be disinclined to choose briquettes. As the results have shown, households currently do not have a strong relative preference for charcoal briquettes over charcoal and kerosene. For those not yet using charcoal briquettes, however, the promotion of its use at the community level can help strengthen their motivation to adopt the fuel on account of its advantages such as low price, longer burning time, and less smoke. That is, the lack of information with regard to access to each energy source might constrain the ability to estimate the energy choice behaviour of households throughout the Kibera slums. Bioenergy and waste management initiatives should promote the recovery of organic by-products for the production of charcoal briquettes.

\section{REFERENCES}

[1] S. Karekezi, "Poverty and energy in Africa-A brief review," Energy Policy, vol. 30, pp. 915-919, 2002.

[2] Kenya Institute for Public Policy Research and Analysis (KIPPRA), The Energy Regulatory Commission (ERC), "A comprehensive study and analysis of energy consumption patterns in Kenya," Synopsis of the Draft Final Report, pp. 6-40, July 2010.

[3] F. Mugo and C. Ong, "Lessons of eastern Africa's unsustainable charcoal trade," ICRAF Working Paper, vol. 20, pp. 1-22, 2006.

[4] S. Mutimba and M. Barasa, "National charcoal survey: Summary Report. Exploring the potential for a sustainable charcoal industry in Kenya," Energy for Sustainable Development Africa (ESDA), pp. 4-22, June 2005.

[5] W. H. Maes and B. Verbist, "Increasing the sustainability of household cooking in developing countries: Policy implications," Renewable and Sustainable Energy Reviews, vol. 16, pp. 4204-4221, May 2012.

[6] E. N. Chidumayo and D. J. Gumbo, "The environmental impacts of charcoal production in tropical ecosystems of the world: A synthesis," Energy for Sustainable Development, vol. 17, pp. 86-94, April 2013.

[7] T. H. Mwampamba, A. Ghilardi, K. Sander, and K. J. Chaix, "Dispelling common misconceptions to improve attitudes and policy outlook on charcoal in developing countries," Energy for Sustainable Development, vol. 17, pp. 75-85, Feb. 2013.

[8] M. Njenga, A. Yonemitsu, and N. Karanja et al., "Implications of charcoal briquette produced by local communities on livelihoods and environment in Nairobi- Kenya," Int. Journal of Renewable Energy Development, vol. 2, no. 1, pp. 19-29, Jan. 2013.

[9] M. Njenga, N. Karanja, G. Prain, J. Malii, P. Munyao, K. Gathuru, and B. Mwasi, "Community-based energy Briquette production from urban organic waste at Kahawa Soweto Informal Settlement, Nairobi," Urban Harvest Working Paper Series, p. 5, Oct. 2009.

[10] M. Arnold, G. Köhlin, and R. Persson, "Woodfuels, livelihoods, and policy interventions: Changing perspectives," World Development 34, no. 3, pp. 596-611, Mar. 2006.

[11] M. Kojima, "The role of liquefied petroleum gas in reducing energy poverty," Oil, Gas, and Mining Policy Unit Working Paper, Extractive Industries for Development Series, vol. 25, Dec. 2011. 
[12] B. Kebede, "Energy subsidies and costs in urban Ethiopia: The cases of kerosene and electricity," Renewable Energy, vol. 31, no. 13, Oct. 2006.

[13] A. Brew-Hammond and F. Kemausuor, "Energy for all in Africa - to be or not to be?" Current Opinion in Environmental Sustainability, vol. 1 , pp. 83-88, Oct. 2009.

[14] O. Masera, B. Saatkamp, and D. Kammen, "From linear fuel switching to multiple cooking strategies: A critique and alternative to the energy ladder model," World Development, vol. 28, no. 12, pp. 2083-2103, Dec. 2000.

[15] A. Mekonnen and G. Köhlin, "Determinants of household fuel choice in major cities in Ethiopia," Working Papers in Economics, vol. 399, pp. $1-18$, Oct. 2009.

[16] J. Nansaior, A. Patanothai, A. T. Rambo, and S. Simaraks, "Climbing the energy ladder or diversifying energy sources? The continuing importance of household use of biomass energy in urbanizing communities in Northeast Thailand," Biomass and Bioenergy, vol. 35, pp. 4180-4188, Oct. 2011.

[17] Nairobi Urban Sector Profile, UN-Habitat., Nairobi, 2006.

[18] S. Karekezi, J. Kimani, and O. Onguru, "Energy access among the urban poor in Keny," Energy for Sustainable Development, vol. 12, no. 4, pp. 38-48, Dec. 2008.

[19] D. McFadden, Conditional Logit Analysis of Qualitative Choice Behavior, New York: Academic Press, 1973, pp. 105-142.

[20] I. Krinsky and A. Robb, "On approximating the statistical properties of elasticities," The Review of Economics and Statistics, vol. 68, no. 4, pp. 715-719, Nov. 1986.

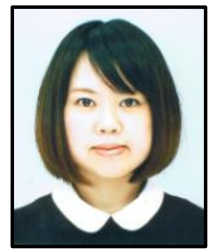

Aya Yonemitsu is pursuing her $\mathrm{PhD}$ degree in agricultural science from the University of Tsukuba, Japan. She is also a research fellow funded by Research fellowship for Young Scientists of Japan Society for the Promotion of Science (JSPS). Her specialty is mainly on agricultural economics and development economics. She has a MSc. degree in agricultural science and a BSc. University of Tsukuba. degree in agricultural resource science from the

Mary Njenga is a post-doctoral fellow in bio-energy at World Agroforestry Centre (ICRAF) Nairobi, Kenya. She earned a PhD degree in management of agroecosystems and environment from the University of Nairobi, Kenya She is also an adjuct assistant professor at the Department of Geography, North Illinois University, USA. She also holds a MSc. degree in conservation biology and a BSc. in natural resource management (NRM). She has over 16 years of experience in research and development in NRM, environment, bioenergy and urban agriculture.

She is a scientist with World Agroforestry Centre (ICRAF) Nairobi, Kenya. She holds PhD in economics from the University of Tokyo, Japan.

She is a faculty member of University of Tsukuba, Japan. She holds PhD in agricultural science from Okayama University, Japan. 